\title{
Clinicoradiological and demographic pattern in diffuse parenchymal lung diseases: An observational study
}

\author{
Yadav $\mathbf{H}^{1}$, Srivastava $\mathbf{R}^{2}$ \\ ${ }^{1}$ Dr. Harendra Yadav, Pulmonary Medicine, KGMU, Lucknow, Uttar Pradesh, ${ }^{2}$ Dr. Rahul Srivastava, Pulmonary \\ Medicine, Assistant Professor, Hind Institute of Medical Sciences, Safedabad, Barabanki, Uttar Pradesh, India.
}

Corresponding Author: Dr. Rahul Srivastava, Pulmonary Medicine, Assistant Professor, Hind Institute of Medical Sciences, Safedabad, Barabanki, Uttar Pradesh. Email: rsrahulvijay6@gmail.com

\begin{abstract}
Introduction: Diffuse parenchymal disease is a group of lung disease affecting alveolar epithelium, pulmonary capillary endothelium, basement membrane, perivascular and perilymphatic tissue. It includes many diseases like IPF, Sarcoidosis, BOOP, COP, LAM etc. it is still under diagnosed entirety. Many patients die due to lack of awareness and investigating modalities. Aims and objective: This study is to see Demographic pattern of DPLD, its clinical pattern and radiological findings in different type of ILDs. Study Type: It is a Prospective Observational Study done over a period of 1 year. Material \& Method: Patients studied over 20 years of age and having respiratory symptoms. We excluded patients of other diseases like COPD, Tuberculosis etc. Total 75 patients were diagnosed as a case of DPLD by clinical findings, and investigations like X ray chest, HRCT thorax, Bronchoscopy. Results: Most common ILD (Interstitial lung Disease) is IPF $40.0 \%$ followed by Sarcoidosis etc. Most common clinical symptom was breathlessness (100.00\%) in IPF, Fever \& Chest Pain are common in Granulomatous type. Conclusion: DPLD (Diffuse Paranchymal lung Disease) is a chronic lung disease characterized by progressive decline in lung function. IPF is most common in DPLD and leads to fast deterioration of lung function. HRCT (High Resolution computed tomography) is very important to assess type of disease. Spirometry, Broncoscopy are important for diagnosis of ILD and lung function.
\end{abstract}

Key words: DPLD, ILD, IPF, Sarcoidosis, Lung, Fibrosis

\section{Introduction}

DPLD is a group of lung disorders having over 200 types of disease. DPLD is characterized by acute or chronic inflammation leading to mild to severe fibrosis [1]. DPLD includes number of disorders like IPF, Sarcoidosis, Hypersensitivity Pneumonitis, LAM, NSIP etc. Diagnosing ILD is not easy, it needs through knowledge and clinical experience. Most definitive diagnostic tool is Histopathology which is not always possible due to lot of factors like patients clinical condition and availability of other diagnostic tools like CT and bronchoscopy.

Now DPLD is diagnosed by clinicoradiological ground because of high quality of High resolution CT, and bronchoscopy, still histopathology is used in many cases where ever feasible. IPF Is most common and having high mortality. The Incidence of DPLD range from12 -26/lacs/year. Prevalence of Preclinical and

Manuscript received: $10^{\text {th }}$ July 2018

Reviewed: $20^{\text {th }}$ July 2018

Author Corrected: $28^{\text {th }}$ July 2018

Accepted for Publication: $2^{\text {nd }}$ August 2018 undiagnosed ILD is estimated to be 10 times of that is clinically recognized disease. The US prospective registry showed that $23 \%$ of cases with ILD were diagnosed with IPF [2]. DPLD is classified in four categories. 1. ILD of Known cause: it includes ILD due to Drugs, Collagen vascular diseases etc. 2. Idiopathic Interstitial Pneumonia. 2a. IPF (idiopathic Pulmonary fibrosis). 2b: Idiopathic pneumonias other than IPF like NSIP (Nonspecific Interstitial Pneumonia), COP (Cryptogenic Organizing Pneumonia), RBILD (Respiratory broncheolitis Interstitial lung disease), DIP (desquamative Interstitial Pneumonia), LIP (Lymphoid Interstitial Pneumonia), AIP (Acute Interstitial pneumonia).

3. Granulomatous DPLD like Sarcoidosis. 4. Other forms like Lymphangioleomyomatosis (LAM), Langerhans Histiocytosis (LH) etc [1\&3]. The IPF was initially considered to be a rare disease in India [4]. Besides IPF other forms like NSIP is common, Most of the times NSIP is associated with connective tissue disorders, 


\section{Original Research Article}

many forms like hypersensitivity pneumonitis are due to hypersensitivity due to pigeon feather and other forms of dusts. DPLD is having variety of diseases which are having many symptoms like cough breathlessness, fever, many connective tissue disorders related DPLDs have other symptoms also like joint pain, Raynod's phenomenon etc. Pedal edema, Cynosis and clubbing is also common in many forms of ILDs. In late and advanced stage of ILD due to development of PAH (Pulmonary artery Hypertension) patient develops raised JVP, and pedal edema. Patient of DPLD if not diagnosed early may land up in Type 1 or type 2 respiratory failure and in further advancement of disease may require Noninvasive or invasive mechanical ventilation. In this study we collect data of frequency and type of DPLD at tertiary care center and clinical profile of patients in various forms.

\section{Aims and Objectives}

To study clinicoradiological pattern and demographic distribution of DPLD in tertiary care center

\section{Material and Method}

Type of Study: Prospective observational study. Place of Study: Patient attending the outdoor/indoor wards of Pulmonary medicine and Rheumatology Department of King George Medical University), Lucknow. Study period From September 2010 to August 2011.

Sampling Method: Patients attending OPD \& IPD Department having clinical symptoms suggestive of interstitial lung disease were taken and through clinical history was taken followed by X-ray, HRCT \& Bronchoscopy was done. Spirometry was done to evaluate lung function.

Patients were divided four groups for study Group 1 granulomatous type were included in having sarcoidosis. Group 2 contains IIP (Idiopathic Interstitial Pneumonia) includes COP (Cryptogenic Organizing Pneumonia), IPF (Idiopathic Pulmonary Fibrosis), NSIP (Non-Specific interstitial Pneumonia).

Group 3: (Known cause) Drug induced BOOP (Bronchiolitis Obliterans Organizing Pneumonia), Drug induced NSIP (Non-Specific interstitial Pneumonia), Silicosis, SLE (Systemic Lupus Erythematosus). Group 4: (Others) EP (Eosinophilic Pneumonia), HP (Hypersensitivity Pneumonitis), LAM (Lymphangioleomyomatosis), LCH (Langerhans cell histiocytosis). [1\&3].
Inclusion Criteria- Age $>20$ Years Patients who had been diagnosed to have different types of DPLD using the American Thoracic Society/European Respiratory Society International Multidisciplinary Consensus Classification of the Diffuse Parenchymal Lung Disease.

Exclusion Criteria- Patients having other associated significant bronchopulmonary disease like:

1. Pulmonary tuberculosis.

2. COPD

3. Bronchiectasis

4. Asthma

5. Pyogenic Pneumonia

6. Bronchogenic carcinoma

7. known HIV positive

8. Patient taking Immunomodulating drugs

Method: After review of clinical history, physical examination along with all investigations, patients were finally included or excluded from the study.

Following methods were employed for study

1.Detailed Clinical History: All the patients were administered a questionnaire regarding the presence of respiratory complaints. These include cough, expectoration, breathlessness, wheezing, chest pain, hemoptysis, stridor and hoarseness of voice. Only the patients with one or any of these symptoms were included in detail.

* Duration of onset of respiratory symptoms.

* Duration between establishment of connective tissue disorder and onset of respiratory symptoms.

* Duration between onset of respiratory symptoms and first visit to physician.

* To which Department (Rheumatology/Pulmonary Medicine) the patient first presented.

* What was the progression of Symptoms.

In how many patients cough was the initial symptom, which was followed by breathlessness and vice-versa. The number of patients in whom fever was the initial symptom followed by cough and breathlessness/ breathlessness and cough was studied.

2. Clinical Examination: General Examination, Respiratory Examination, Rheumatological Examination, Systemic Examination.

3. Investigations: It includes Routine hemogram, Serum biochemistry, Chest radiograph, High resolution Tomography of thorax, Bronchoscopy with Bronchoalveolar lavage and Transbronchial lung biopsy, Spirometry with DL Co (Diffusion capacity of lung Carbon monoxide). 
Statistical tools: The statistical analysis was done using SPSS (statistical Package for social sciences) Version 15.0 statistical Analysis Software. The values were represented in Number (\%) and Mean \pm SD.
The following Statistical formulas were used:

1. Mean

2. Standard Deviation

3. Analysis of Variance:

\section{Results}

Table-1: Showing different types of DPLDs seen in this study.

\begin{tabular}{|c|c|c|c|}
\hline S.N. & Type & No. of Patients & Percentage \\
\hline 1 & Idiopathic Pulmonary Fibrosis & 30 & 40.00 \\
\hline 2 & Sarcoidosis & 16 & 21.3 \\
\hline 3 & Non-Specific interstitial Pneumonia & 5 & 6.7 \\
\hline 4 & Rheumatoid Arthritis & 5 & 6.7 \\
\hline 5 & Systemic Lupus Erythematosus & 3 & 4 \\
\hline 6 & Systemic Sclerosis & 3 & 4 \\
\hline 7 & Cryptogenic Organizing Pneumonia & 2 & 2.7 \\
\hline 8 & Eosinophilic Pneumonia & 2 & 2.7 \\
\hline 9 & Hypersensitivity Pneumonitis & 2 & 2.7 \\
\hline 10 & Lymphangioleomyomatosis & 2 & 2.7 \\
\hline 11 & Silicosis & 1 & 2.7 \\
\hline 12 & $\begin{array}{c}\text { Drug Induced Bronchiolitis Obliterans } \\
\text { Organizing Pneumonia }\end{array}$ & 1 & 1.3 \\
\hline 13 & $\begin{array}{c}\text { Drug Induced Non-Specific Interstitial } \\
\text { Pneumonia }\end{array}$ & 1 & 1.3 \\
\hline 14 & Langerhans cell histiocytosis & 1 & 1.3 \\
\hline
\end{tabular}

Maximum number of cases were found of Idiopathic pulmonary fibrosis and followed by sarcoidosis and minimum cases of silicosis, Drug induced BOOP, Drug induced NSIP and Langerhans cell histiocytosis.

Table-2: Distribution of patients according to Grouped Diagnosis

\begin{tabular}{|c|c|c|c|}
\hline S.N. & Grouped Diagnosis & No. of Patients & Percentage \\
\hline 1 & Group I (Granulomatous) (All cases of sarcoidosis & 16 & 21.2 \\
\hline 2 & Group I (IIP) (COP, IPF, NSIP) & 37 & 20.00 \\
\hline 3 & Group III (Known) (Drug induced BOOP, Drug induced & 15 & 9.3 \\
\hline 4 & NSIP, Silicosis, SLE & 7 & 2 \\
\hline
\end{tabular}

Table showing maximum number of patients fall under Group II having Idiopathic interstitial pneumonias, second most common group is Group I containing granulomatous type of diseases like sarcoidosis, Group III is having only $20 \%$ of patients, Group IV is least common among all DPLDs. 
Original Research Article

Table-3: Distribution of patients according to Demography includes age, sex, occupation etc.

\begin{tabular}{|c|c|c|c|c|c|c|c|c|c|c|c|}
\hline \multirow[t]{2}{*}{ S.N. } & \multirow[t]{2}{*}{$\begin{array}{c}\text { Characterist } \\
\text { ics }\end{array}$} & \multicolumn{2}{|c|}{$\begin{array}{c}\text { Group I } \\
(n=37)\end{array}$} & \multicolumn{2}{|c|}{ Group II (n=15) } & \multicolumn{2}{|c|}{ Group III (n=15) } & \multicolumn{2}{|c|}{$\begin{array}{c}\text { Group IV } \\
(n=7)\end{array}$} & \multicolumn{2}{|c|}{$\begin{array}{l}\text { Significance of } \\
\text { difference }\end{array}$} \\
\hline & & No & $\%$ & No. & $\%$ & No. & $\%$ & No. & $\%$ & $x^{2}$ & $P$ \\
\hline 1 & $\begin{array}{l}\text { Mean Age }{ }^{+}- \\
\text {SD (Range) }\end{array}$ & \multicolumn{2}{|c|}{$\begin{array}{c}37.06^{+}-10.45 \\
(25.65)\end{array}$} & $\begin{array}{c}55.57^{+}-8.07 \\
(35-70)\end{array}$ & & $\begin{array}{c}49.33^{+}-7.53 \\
(35-60)\end{array}$ & & \multicolumn{2}{|c|}{$\begin{array}{c}40.17^{+}-12.05 \\
(30-60)\end{array}$} & \multicolumn{2}{|c|}{$\begin{array}{c}F=18.272 \\
P<0.001\end{array}$} \\
\hline \multirow{3}{*}{2} & Gender & & & & & & & & & & \\
\hline & Male & 7 & 43.8 & 22 & 59.5 & 5 & 33.3 & 3 & 42.9 & \multirow{2}{*}{3.371} & \multirow{2}{*}{0.338} \\
\hline & Female & 9 & 56.3 & 15 & 40.5 & 10 & 66.7 & 4 & 57.1 & & \\
\hline 3 & Smoke & 1 & 6.3 & 13 & 35.1 & 2 & 13.3 & 2 & 28.6 & 6.295 & 0.098 \\
\hline \multirow{5}{*}{4} & Education & & & & & & & & & & \\
\hline & Illiterate & 2 & 12.5 & 18 & 48.6 & 6 & 40.00 & 1 & 14.3 & \multirow{4}{*}{12.488} & \multirow{4}{*}{0.187} \\
\hline & Primary & 0 & 0.00 & 2 & 5.4 & 0 & 0.00 & 0 & 0.00 & & \\
\hline & HS/Inter & 6 & 37.5 & 9 & 24.3 & 6 & 40.00 & 3 & 42.9 & & \\
\hline & $\begin{array}{c}\text { Graduate \& } \\
\text { Above }\end{array}$ & 8 & $\begin{array}{c}50.0 \\
0\end{array}$ & 8 & 21.6 & 3 & 20.00 & 3 & 42.9 & & \\
\hline \multirow{4}{*}{5} & Occupation & & & & & & & & & & \\
\hline & Housewife & 8 & $\begin{array}{c}50.0 \\
0\end{array}$ & 12 & 32.4 & 7 & 46.7 & 3 & 42.9 & \multirow{3}{*}{8.097} & \\
\hline & $\begin{array}{l}\text { Agriculture/ } \\
\text { Labour }\end{array}$ & 0 & 0.00 & 13 & 35.1 & 4 & 26.7 & 2 & 28.6 & & \\
\hline & Service & $8 *$ & $\begin{array}{c}50.0 \\
0\end{array}$ & 12 & 32.4 & 4 & 26.7 & 2 & 28.6 & & \\
\hline
\end{tabular}

Table-4: Distribution of patients according to Clinical Findings.

\begin{tabular}{|c|c|c|c|c|c|c|c|c|c|c|c|}
\hline S.N. & Characteristics & \multicolumn{2}{|c|}{$\begin{array}{c}\text { Group I } \\
(\mathbf{n = 1 6})\end{array}$} & \multicolumn{2}{|c|}{$\begin{array}{c}\text { Group II } \\
(\mathbf{n = 3 7})\end{array}$} & \multicolumn{2}{|c|}{$\begin{array}{c}\text { Group III } \\
(\mathbf{n = 1 5})\end{array}$} & \multicolumn{2}{|c|}{$\begin{array}{c}\text { Group IV } \\
(\mathbf{n = 7})\end{array}$} & \multicolumn{2}{c|}{$\begin{array}{c}\text { Significance of } \\
\text { difference }\end{array}$} \\
\hline & & No. & $\%$ & No. & $\%$ & No. & $\%$ & No. & $\%$ & $x^{2}$ & P \\
\hline $\mathbf{1}$ & Chest Pain & 9 & 56.2 & 3 & 8.1 & 3 & 20 & 1 & 14.3 & 15.703 & 0.001 \\
\hline $\mathbf{2}$ & Fever & 11 & 81.30 & 2 & 5.4 & 4 & 26.7 & 2 & 28.6 & 23.765 & $<0.001$ \\
\hline $\mathbf{3}$ & Dry cough & 4 & 25 & 15 & 40.5 & 4 & 26.7 & 1 & 14.3 & 2.806 & 0.422 \\
\hline $\mathbf{4}$ & Breathlessness & 5 & 31.2 & 37 & 100 & 12 & 80 & 7 & 100 & 36.55 & $<0.001$ \\
\hline $\mathbf{5}$ & Pedal edema & 1 & 6.3 & 7 & 18.9 & 0 & 0 & 0 & 0 & 5.599 & 0.133 \\
\hline $\mathbf{6}$ & Cyanosis & 1 & 6.3 & 14 & 37.8 & 0 & 0 & 0 & 0 & 14.749 & 0.002 \\
\hline $\mathbf{7}$ & Lymphadenopathy & 5 & 31.3 & 0 & 0 & 0 & 0.00 & 0 & 0 & 19.754 & $<0.001$ \\
\hline $\mathbf{8}$ & Clubbing & 0 & 0.00 & 19 & 52.3 & 2 & 13.30 & 0 & 0.00 & 20.553 & $<0.001$ \\
\hline $\mathbf{9}$ & JVP R & 0 & 0 & 8 & 21.6 & 1 & 6.70 & 0 & 0 & 6.784 & 0.079 \\
\hline $\mathbf{1 0}$ & Other & 2 & 12.50 & 0 & 0 & 12 & 80.00 & 1 & 14.3 & 43.705 & $<0.001$ \\
\hline
\end{tabular}

This table Showing clinical symptoms in different of DPLDs. Breathless is most common complaint, Constitutional symptom like fever and chest pain are more common in DPLDs associated with connective tissue disorders. 


\section{Discussion}

DPLD is a group of diseases which include IPF, Sarcoidosis and many other forms. In this study total 75 patients were assessed clinically as well as radiologically with Spirometry and DLCO. Best approach to patients with DPLD begins with careful history and examinations followed by Chest radiographs and Pulmonary function test [5]

After careful history and examinations along with investigations we found total 14 types of DPLD (Table1). For the study we divided the DPLDs in four Groups (Table-2). Group I (Granulomatous) all sarcoidosis contains 16 patients (21.3\%). Group II (IIP) COP, IPF, NSIP contains 37 patients (49.3\%). Group III (Known, BOOP, Drug induced, Silicosis, SLE etc) contains 15 patients, Group IV (others EP, HP, LAM, LCH) contains 7 patients (9.3\%). In our study Group II containing maximum number of patients $49.3 \%$. next most common group diagnosed was Group I (granulomatous, all cases were sarcoidosis. Total 30 (40.0\%) patients were diagnosed as IPF. Sarcoidosis $16(1.3 \%)$, NSIP $5(6.7 \%)$ etc. The yearly prevalence of IPF was 20.2 per 100,000 population in males and 13.2 per 100,000 populations in females. [13]. the study referenced [13] shows maximum no. of patients with IPF followed by Sarcoidosis is comparable to our study.

Demographic distribution is done in Table 3. Showing age of patients ranged from 25 to 70 years. Mean age of subjects in group I was minimum $(37.06+/-10.45$ years) while that of Group II was maximum $(55.57+/-8.07$ years). On comparing data a significant Difference among groups was observed $(\mathrm{p}<0.001)$. There is no significant intergroup difference was observed between male and female $(\mathrm{p}<0.338)$. The proportion of Smokers ranged $12.5 \%$ in group I to $48.6 \%$ in group II, however despite this inter group variability, Statistical difference was not significant.

In Table-4 Distribution of patients according to clinical findings was observed. In group I Fever (81.3\%) and chest pain (56.2\%) were most common clinical findings as compared to other groups. These were significantly higher in group I.The incidence of patients with breathlessness in this group was lower as compared to other groups. Whereas all the patients had breathlessness. In Group II breathlessness was the most common finding $(100 \%)$. Other common findings were Clubbing (52.3\%) and cyanosis (37.8\%). In Group III all the patients had Breathlessness. Group III had many associated problems. Categorized together as others.
The incidence of other findings (80\%) was significantly higher in group III as compared to other groups. In Group IV all the subjects had breathlessness.

The clinical history includes the symptoms like breathlessness, cough etc \& their progression and clinical course. Comorbid diseases like collagen vascular disease should be sought in mind in case of DPLDs associated with SLE (Systemic Lupus Erythematosus) \& RA (Rheumatoid Arthritis). A record of environmental factors like smoking status, drug use and occupational history is important to diagnose ILD associated with occupational Lung Diseases.

Physical examination is very important and sings like finger clubbing, cyanosis, reynods phenomenon must be evaluated. in case of joint pain and tight skin collagen vascular diseases must be assessed. After detailed history and examination investigation must include chest radiograph, High resolution CT. Further bronchoscopy with Bronchoalveolar lavage, Transbronchial lung biopsy, Endobronchial biopsy should be done. For assessment of lung function Pulmonary function test and DLco are important investigating tools.

HRCT (High resolution CT) should be done with established Guidelines [ $6 \&$ \%]. In more than $50 \%$ cases suspected of IPF (idiopathic pulmonary fibrosis) the presence of typical clinical and HRCT features of UIP (usual interstitial pneumonia) that is honey combing and lower subpleural predominance is sufficient to allow a confidant diagnosis of IPF and it eliminates need of surgical lung biopsy [8 \& 5]. HRCT (High resolution CT) also provide important clues for NON-IIP diseases like Sarcoidosis [9]. DPLD affects not only interstitial space but also the air spaces, Peripheral airways, and vessels along with epithelial and endothelial linings [10]. Patients are commonly misclassified as IIP because of Inadequate history and examinations. There are increased association between the development of DPLD and Occupational, environmental and drug exposure [11,12].

Connective tissue disorder related DPLDs belong to Lower age group patients [14]. In this study mean age for diseases associated with Connective tissue disorder is 49.33 years. Pulmonary Symptom and sign among CTD-ILD were similar to IPF, except clubbing, which is uncommon in CTD related ILDs [15]. The annual prevalence of Idiopathic pulmonary fibrosis was 20.2 


\section{Original Research Article}

per 100000 population in males and 13.2 per 100000 in females [2]. IPF is also found in maximum number in this study. Number of clinicopathological types, they are sufficiently different from one another designated as separate disease. they can be clearly distinguished from others by detailed clinical history and examinations, chest radiology and other laboratory findings.

India is a high burden country for tuberculosis. Many patients with Interstitial disease are mis diagnosed to be with Tuberculosis and receive antitubercular drugs. [14]. So clinical history and investigations including sputum microscopy for acid fast bacilli is very important to rule out Tuberculosis.

\section{Conclusion}

Diffuse parenchymal lung disease is a group of multiple disorders. Clinical presentation of different types is almost similar which includes symptoms like breathlessness, dry cough, along with systemic symptoms like fever, chest pain etc, joint pain and other constitutional symptoms are more common in connective tissue disorders related DPLDs. Clinical history and radiology is very important for correct diagnosis of DPLDs. [5].

Idiopathic interstitial pneumonia is more common. Idiopathic pulmonary fibrosis is most common entity followed by granulomatous disease like sarcoidosis. High resolution computed tomography (HRCT) thorax is very important and in case of good clinical history and examination a good quality HRCT thorax can leads near precise diagnosis and eliminate need of Biopsy [8 \& 9].

What the study adds to existing knowledge: DPLDs are not properly diagnosed till date due to lack of proper data. There is no cure for many types of DPLDs. This study confirms the data which were already present and strengthens the need of good clinical evaluation and radiological findings. As biopsy is not possible in each and every case due to many reasons, clinical and radiological evaluation is important in diagnosis of different type of DPLDs.

Authors Contribution: (1) Dr. Harendra Yadav: Selection of patients, their clinical evaluation and investigations was done by Dr Harendra Yadav. Helped in manuscript writing. (2) $\mathrm{Dr}$ Rahul Srivastava: Collection and compilation of data, evaluation and interpretation of master chart, review of literature and references were obtained by Dr Rahul Srivastava. Manuscript writing is done by Dr Rahul Srivastava.

\section{Funding: Nil, Conflict of interest: None} Permission of IRB: Yes

\section{References}

1. Raghu G. Interstitial lung disease. In: Goldman L, Schafer AI, editors Cecil Medicine; 24th editon. Philadelphia: W.B. Saunders; 2011: pp556-66.

2. Coultas DB, Zumwalt RE, Black WC, Sobonya RE. The epidemiology of interstitial lung diseases. DOI:10. 1164/ ajrccm.150.4.7921471.

3. Morgenthau AS, Padilla ML. Spectrum of fibrosing diffuse parenchymal lung disease. DOI:10.1002/msj. 20087.

4. Jindal SK, Malik SK, Deodhar SD, Sharma BK. Fibrosing alveolitis: a report of 61 cases seen over the past five years. Indian J Chest Dis Allied Sci. 1979 OctDec; 21(4):174-9.

5. Raghu G, Mageto YN, Lockhart D, et al. The accuracy of the clinical diagnosis of new-onset idiopathic pulmonary fibrosis and other interstitial lung disease: A prospective study. Chest. 1999 Nov;116(5): 1168-74.

6. American College of Radiology. Practice guideline for the breast conservation therapy in the management of invasive breast carcinoma. DOI: 10. 1016/j. jamcollsurg. 2007.02.057

7. Austin JH, Müller NL, Friedman PJ, et al. Glossary of terms for CT of the lungs: recommendations of the Nomenclature Committee of the Fleischner Society. DOI: $10.1148 /$ radiology.200.2.8685321

8. Hunninghake GW, Zimmerman MB, Schwartz DA, et al. Utility of a lung biopsy for the diagnosis of idiopathic pulmonary fibrosis. DOI: $10.1164 /$ ajrccm. 164. 2.2101090.

9. Honda O, Johkoh T, Ichikado K, et al. Comparison of high resolution CT findings of sarcoidosis, lymphoma, and lymphangitic carcinoma: is there any difference of involved interstitium? J Comput Assist Tomogr. 1999 May-Jun;23(3):374-9.

10. Cushley MJ, Davison AG, du Bois RM, Egan J, Flower CD, Gibson GJ, Greening AP, Ibrahim NB, Johnston ID, Mitchell DM, et al. The diagnosis, assessment and treatment of diffuse parenchymal lung disease in adults. Thorax 1999;54:S1-S30. 


\section{Original Research Article}

11. Hubbard R, Venn A, Smith C, et al. Exposure to commonly prescribed drugs and the etiology of cryptogenic fibrosing alveolitis: a case-control study. DOI:10.1164/ajrccm.157.3.9701093

12. Scott J, Johnston I, Britton J. What causes cryptogenic fibrosing alveolitis? A case-control study of environmental exposure to dust. BMJ. 1990 Nov 3;301 (6759):1015-7.

13. Kundu S, Mitra S, Ganguly J, et al. Spectrum of diffuse parenchymal lung diseases with special reference to idiopathic pulmonary fibrosis and connective tissue disease: An eastern India experience. DOI:10.4103/0970-2113.142115

14. Udwadia ZF, Sen T, Jindal SK. Interstitial lung diseases in a resource-limited setting: The case of India. Eur Respir Mon 2009;46:357-74.

15. Rajasekaran BA, Shovlin D, Lord P, et al. Interstitial lung disease in patients with rheumatoid arthritis: a comparison with cryptogenic fibrosing alveolitis. Rheumatology (Oxford). 2001 Sep; 40 (9): 1022-5.

\section{How to cite this article?}

Yadav H, Srivastava R. Clinicoradiological and demographic pattern in diffuse parenchymal lung diseases: An observational study. Int J Med Res Rev 2018;6(06):308-314.doi:10.17511/ijmrr. 2018.i06.03. 